\title{
Minor adverse events postcolonoscopy
}

\author{
Catherine Dubé MD MSc FRCPC
}

In recent years, the Canadian Journal of Gastroenterology and Hepatology has provided its readership with multiple publications to further our understanding of what constitutes a high-quality procedure as well as a desirable colonoscopy experience $(1-4)$. In the current issue of the Journal, the study by Marquez Azalgara et al (5) (pages 595 . 599) enhances our understanding of yet another facet of quality colonoscopy by documenting the rates and types of postcolonoscopy minor adverse events (MAEs) occurring in the early (two days) and late (14 and 30 days) postcolonoscopy period. The major points to note from the study are that: patients commonly experienced MAEs after colonoscopy, with $17.3 \%$ (95\% credible interval [CrI] $8.1 \%$ to $30 \%$ ) of participants reporting at least one MAE at two days postcolonoscopy; these MAEs may last for several weeks postcolonoscopy, with $10.5 \%$ (95\% $\mathrm{CrI} 2.9 \%$ to $23.7 \%$ ) of participants reporting at least one MAE at 14 days; and the most common type of postcolonoscopy MAE is abdominal pain (reported by $8.6 \%$ and $4.1 \%$ of respondents at two days and 14 days, respectively).

One major caveat to note about any study investigating postcolonoscopy MAEs is that a large proportion of the patients undergoing colonoscopy will have experienced frequent abdominal symptoms before the procedure, as described by the authors. Postcolonoscopy MAEs may, therefore, be attributable to an underlying condition. While clinicians may be concerned about the need to attribute the symptoms to either the procedure, the underlying condition of the patient, or both, this attribution may not be relevant to the patient, whose experience nevertheless remains. In this way, the study by Marquez Azalgara et al (5) furthers our awareness of the patient's experience with colonoscopy. This knowledge can, in turn, help the informed consent process by enabling us to inform patients of what to expect not solely on the day of the procedure, but also afterward. When asked about their expectations of a high-quality colonoscopy service, focus group participants expressed a desire to obtain as much information as possible about the procedure, including what to expect after the procedure (4). It is also common to observe that the anxiety triggered by not knowing what to expect may be perceived as worse than the symptoms themselves. This information can also be provided to patients on discharge from the endoscopy unit, and may help reduce the need for patients to contact a health care provider regarding these MAEs.

Postcolonoscopy abdominal pain is a symptom to reflect on. It was experienced by $8.6 \%$ of participants in the Marquez Azalgara et al (5) study, while other recent studies noted it in $11 \%$ to $17 \%$ of patients $(6,7)$. Based on these reports, this pain typically lasts up to 14 days and rarely prompts patients to seek medical advice. We can, therefore, assume that it is mild and not associated with concerning symptoms such as bleeding, vomiting or abdominal pain. How can we best understand the cause of this pain? Its duration is well beyond that which would be caused by retained air and, even moreso, retained carbon dioxide. One can conceive that this pain is triggered by minor soft tissue trauma caused by pressure and traction forces applied to the colon during the procedure. Such trauma is probably limited to the colonic wall and adjacent mesentery in most cases, but has been related to lifethreatening injuries such as splenic rupture (8). It is interesting to note that the forces applied to the colonoscope during insertion and withdrawal can now be measured with the help of special devices attached to the scope $(9,10)$. Significant differences in the measured push/pull force and torque values among endoscopists and along the length of the colon have been demonstrated (9). Recently, a comparison of the forces applied to the colonoscope during procedures performed with either moderate sedation (with a combination of meperidine or fentanyl and midazolam) or with propofol, demonstrated significant increases in peak and average force when sedation with propofol was used (10). It was assumed that this difference was related to the method of scope insertion and withdrawal with propofol, in which patient feedback is absent and the ability to reposition the patient is limited. In that study, the magnitude of forces observed were noted, in some cases, to be greater than the tear and perforation forces one can measure on surgical or cadaveric specimens. The authors noted a need to further study the rates of postcolonoscopy adverse events, and to study the correlation of force with clinical outcomes such as postcolonoscopy pain. If an association between postcolonoscopy pain and the intensity of the forces applied during colonoscopy is observed, the monitoring of postcolonoscopy pain will become highly relevant to practices that use propofol. More importantly, this would reinforce the increasingly recognized need to redefine endoscopy skills as those that allow minimal pressure and loop reduction.

In conclusion, it is important to recognize the occurrence of postcolonoscopy MAEs and to make patients aware of them. This further improves the informed consent process. Further research into the relationship between postcolonoscopy MAEs, sedation practices and procedural skills is needed.

\section{REFERENCES}

1. Armstrong D, Barkun A, Bridges R, et al. Canadian Association of Gastroenterology consensus guidelines on safety and quality indicators in endoscopy. Can J Gastroenterol 2012;26:17-31.

2. Tinmouth J, Kennedy EB, Baron D, et al. Colonoscopy quality assurance in Ontario: Systematic review and clinical practice guideline. Can J Gastroenterol Hepatol 2014;28:251-74.

3. Borgaonkar MR, Hookey L, Hollingworth R, et al. Indicators of safety compromise in gastrointestinal endoscopy. Can J Gastroenterol 2012;26:71-8.

4. Sewitch MJ, Dubé C, Brien S, et al. Patient-identified quality indicators for colonoscopy services. Can J Gastroenterol 2013;27:25-32.

5. Marquez Azalgara V, Sewitch M, Joseph L, Barkun AN. Rates of minor adverse events and health resources utilization postcolonoscopy. Can J Gastroenterol Hepatol 2014;28:595-9.

6. Ko CW, Riffle S, Shapiro JA, et al. Incidence of minor complications and time lost from normal activities after screening or surveillance colonoscopy. Gastrointest Endosc 2007;65:648-56.

7. de Jonge V, Sint Nicolaas J, van Baalen $\mathrm{O}$, et al. The incidence of 30-day adverse events after colonoscopy among outpatients in the Netherlands. Am J Gastroenterol 2012;107:878-84.

8. Michetti CP, Smeltzer E, Fakhry SM. Splenic injury due to colonoscopy: analysis of the world literature, a new case report, and recommendations for management. Am Surg 2010;76:1198-204.

9. Korman LY, Egorov V, Tsuryupa S, et al. Characterization of forces applied by endoscopists during colonoscopy by using a wireless colonoscopy force monitor. Gastrointest Endosc 2010;71:327-34.

10. Korman LY, Haddad NG, Metz DC, et al. Effect of propofol anesthesia on force application during colonoscopy. Gastrointest Endosc 2014;79:657-62.

Department of Medicine, Division of Gastroenterology, University of Ottawa, Ottawa, Ontario

Correspondence: Dr Catherine Dubé, Department of Medicine, Division of Gastroenterology, University of Ottawa, Room A194,

The Ottawa Hospital - Civic Campus, 1053 Carling Avenue, Ottawa, Ontario K1Y 4E9. E-mail cdube@toh.on.ca

Received and accepted for publication November 27, 2014 


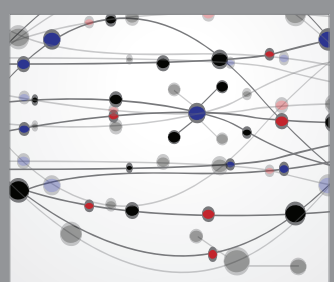

The Scientific World Journal
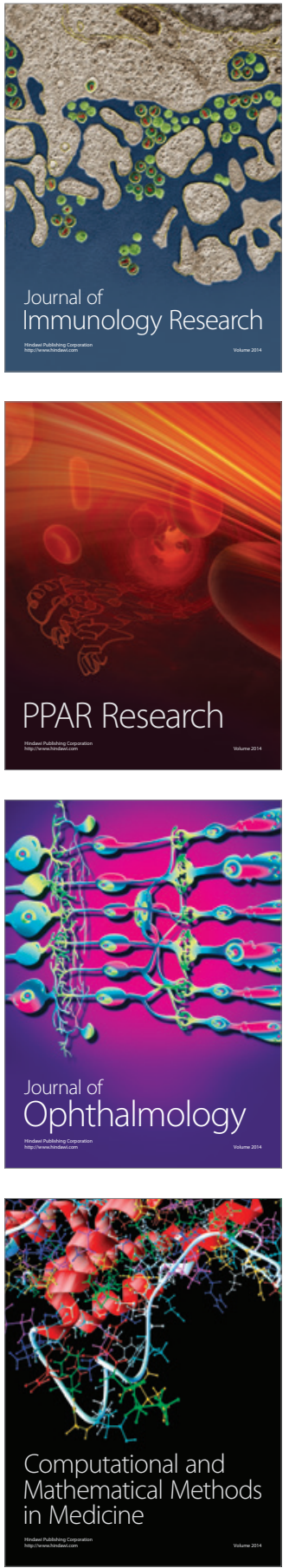

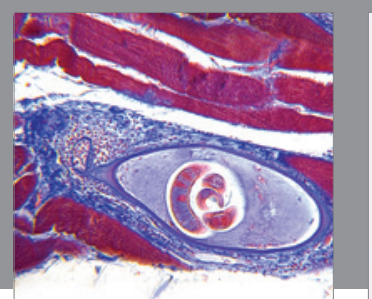

Gastroenterology Research and Practice

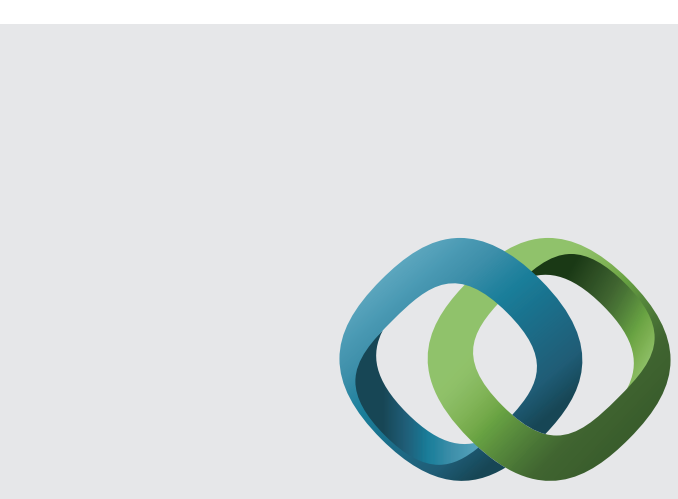

\section{Hindawi}

Submit your manuscripts at

http://www.hindawi.com
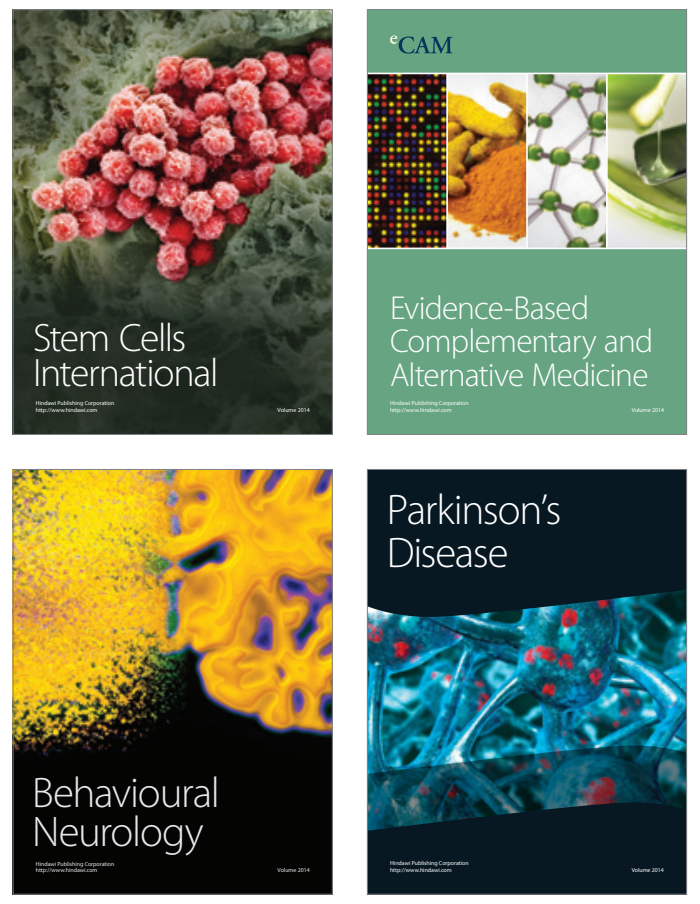
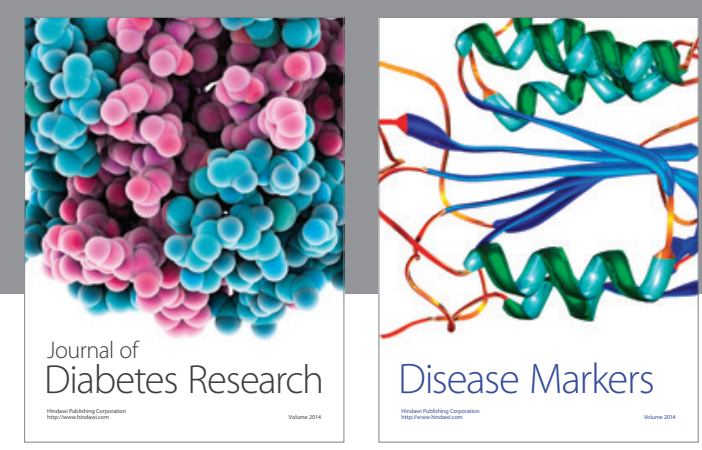

Disease Markers
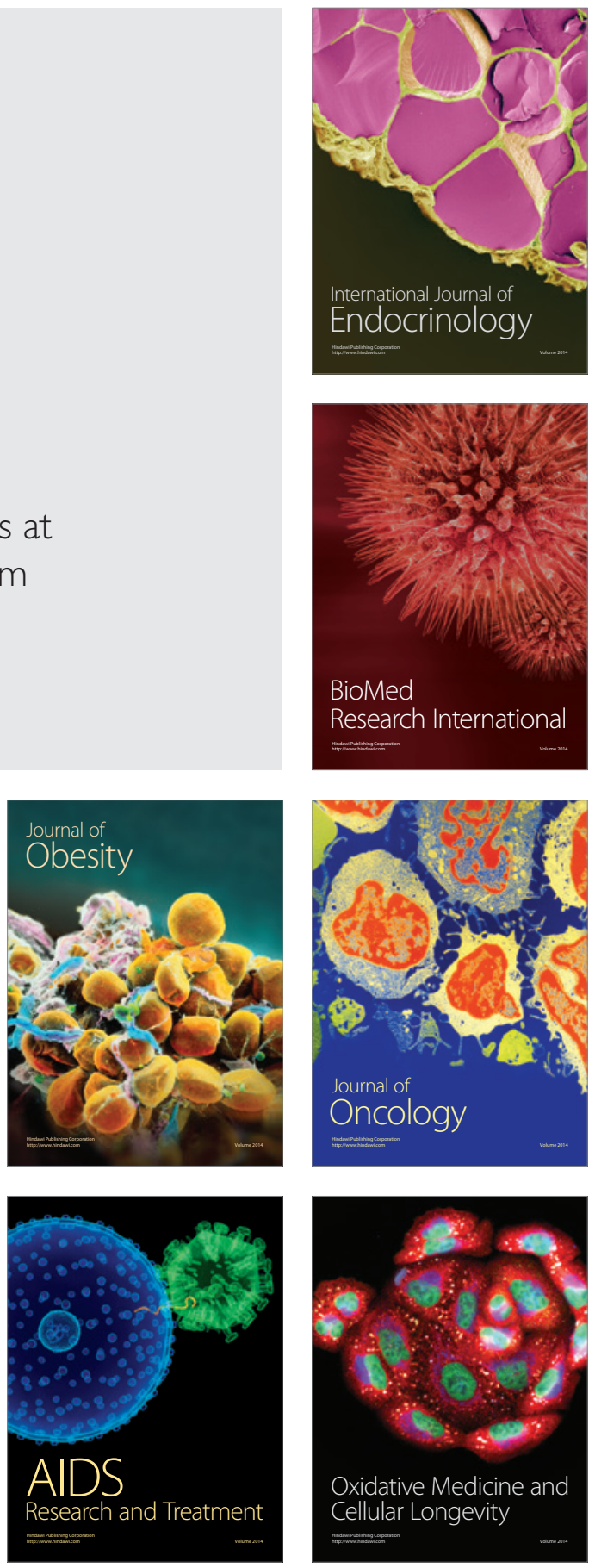